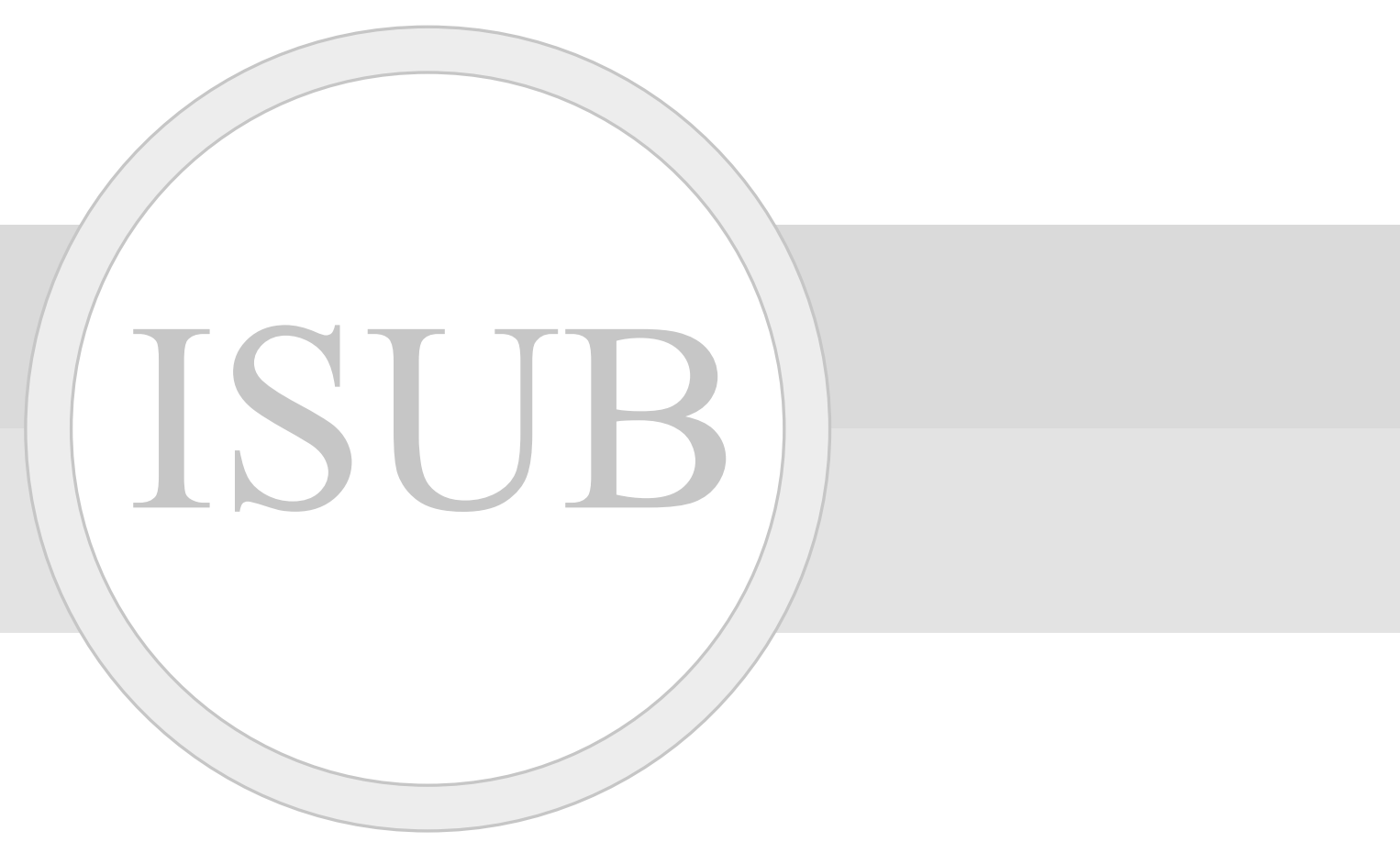




\title{
EDITORIAL
}

\author{
Atilio Junior Ferrebuz Cardozo \\ Docente Investigador, Programa de Medicina, Facultad de Ciencias de la Salud Universidad de Boyacá, Tunja, Colombia. \\ Correspondencia: Dirección: Carrera 2 Este № 64-169 Tunja, Boyacá, Colombia; Teléfono 7450000 ext 4401. \\ Correo electrónico: ajferrebuz@uniboyaca.edu.co \\ DOI: https: //doi.org/10.24267/23897325.352
}

\section{La Investigación en Colombia: una perspectiva hacia el futuro}

La investigación es un proceso riguroso y estructurado que tiene como objetivo principal aumentar los conocimientos que se tienen sobre un tema o una problemática. Desde hace muchos años los estados y sus instituciones han iniciado un proceso para fortalecer y promover la investigación en sus territorios, sin embargo, los resultados obtenidos de estas políticas no son homogéneos en el mundo; empleando datos obtenidos de SCImago Journal \& Country Rank (1) evaluando el año 2016 observamos como los estados de Norteamérica (Estados Unidos y Canadá) generaron 555.039 y 90693 documentos citables respectivamente, para una total de 645.732 documentos. Por otra parte, Inglaterra, Alemania, Francia, Italia y España lideran la producción de artículos citables en Europa con 6.610 .303 documentos. En Latinoamérica este ranking lo lidera Brasil con 68.741 documentos citables, México con 21.224, Argentina con 12.266, Chile con 11.802, y cierran los 5 primeros lugares Colombia con 10.191 documentos, para un total de 124.224 documentos en los primeros 5 países. Es evidente la brecha en producción de nuevo conocimiento que se presenta Latinoamérica en los datos mostrados, la pregunta es, ¿Por qué tanta diferencia? ¿Cuál es la limitante?

Información del Banco Mundial (2) en el 2016 reporta la inversión para investigación y desarrollo, en donde podemos ver que los países de Europa destinaron para este rubro entre 1,185 y 2,93\% del Producto Interno Bruto (PIB), por su parte Estados Unidos y Canadá aportaron 2,74 \% y 1,61\% del PIB respectivamente, mientras que en Latinoamérica se destina entre 0,25 y $0.63 \%$ del PIB en este año; aquí ya observamos una clara diferencia en el presupuesto que los estados destinan para actividades de investigación y desarrollo al comparar Latinoamérica con en otras regiones, analizando una correlación entre el presupuesto asignado y los documentos citables generados por cada país en el año 2016. 
Este análisis permitió evidenciar la relación existente entre estas dos variables, estableciendo tres grupos claramente definidos en relación a los recursos económicos disponibles y el producto de estos; así la mayoría de los estados Latinoamericanos analizados (México, Argentina, Chile, Colombia, Ecuador, Venezuela y Uruguay) se encuentran en el grupo con menor inversión y menor producción documental, seguido con un grupo de producción moderada donde se encuentra Canadá de Norteamérica, Francia, Italia y España de Europa, resaltando a Brasil como el único país latinoamericano que ingresa a este grupo e invierte un porcentaje del PIB similar a Italia y España. Finalmente, se muestra un tercer grupo de máxima producción liderado por Estados Unidos con más de 500.000 documentos, y seguidos por Inglaterra y Alemania con poco más de 150.000 documentos cada uno; siendo Alemania y Estados Unidos los que más invierten en investigación y desarrollo, con 2,939\% y 2,744 \% del PIB respectivamente.

Uno de los retos a la investigación y desarrollo en Colombia se desprende de este análisis, donde el presupuesto dedicado representa un factor que puede condicionar la producción científica, y nos puede dar una lectura indirecta de las políticas de Investigación y desarrollo adelantadas por el estado. Para profundizar en el contexto Colombiano, según datos del Banco Mundial (2), en el periodo de 2006 a 2016, el estado colombiano ha apostado por un incremento de los recursos de inversión para Investigación y desarrollo, pasando de $0.149 \%$ del PIB en el 2006 a $0.271 \%$ del PIB en 2016, con un máximo de $0.301 \%$ del PIB en el 2014 , evidenciado un aumento de $81 \%$ en el porcentaje del PIB para la inversión en este sector en 10 años. La pregunta clave en este momento sería ¿Existe un aumento en la producción de documentos citables?

Al revisar en las bases de datos de SCImago Journal \& Country Rank (1) la producción de documentos citables generados en Colombia, se evidencia que en 2006 se generaron 2.036 documentos citables y en 2016 se generaron 9.539 documentos citables, lo que representa un incremento $368 \%$ en la producción documental nacional. Esto soporta que en Colombia los cambios en la inversión y las políticas de investigación y desarrollo adelantadas en estos 10 años han potenciado considerablemente este sector, y se debe mantener esta ruta en los años venideros.

Todo lo expuesto evidencia una tendencia positiva para la investigación en Colombia, ya que los datos nos brindan una perspectiva de crecimiento en el futuro y aunque aún estamos muy lejos de posicionarnos entre los países con producción documental moderada como actualmente lo hace Brasil, en 
Latinoamérica ya nos posicionamos en el quinto lugar y la meta deber ser mejorar y ascender cada año. Está claro que el estado debe continuar con las mejoras en las políticas de investigación y desarrollo, pero no podemos olvidar el compromiso de nosotros los investigadores, a realizar trabajos de calidad, ser propositivos, ser resilientes y dinámicos en los procesos que se ejecutan al interior de las instituciones en las que adelantamos nuestras investigaciones.

\section{REFERENCIAS}

1. SCImago (n.d.). SJR - SClmago Journal \& Country Rank [Portal] [Internet]. 2018 [cited 2018 Oct 25]. Available from: http://www.scimagojr.com

2. Mundial B. Gasto en investigación y desarrollo (\% del PIB) [Internet]. 2018 [cited 2018 Dec 11]. Available from: https://datos.bancomundial. org/tema/ciencia-y-tecnologia?end $=2016 \&$ locations $=$ CA-GB-US\&start $=1996 \&$ view $=$ chart

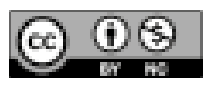

Esta obra está bajo una licencia de Creative Commons Reconocimiento-NoComercial 4.0 Internacional 


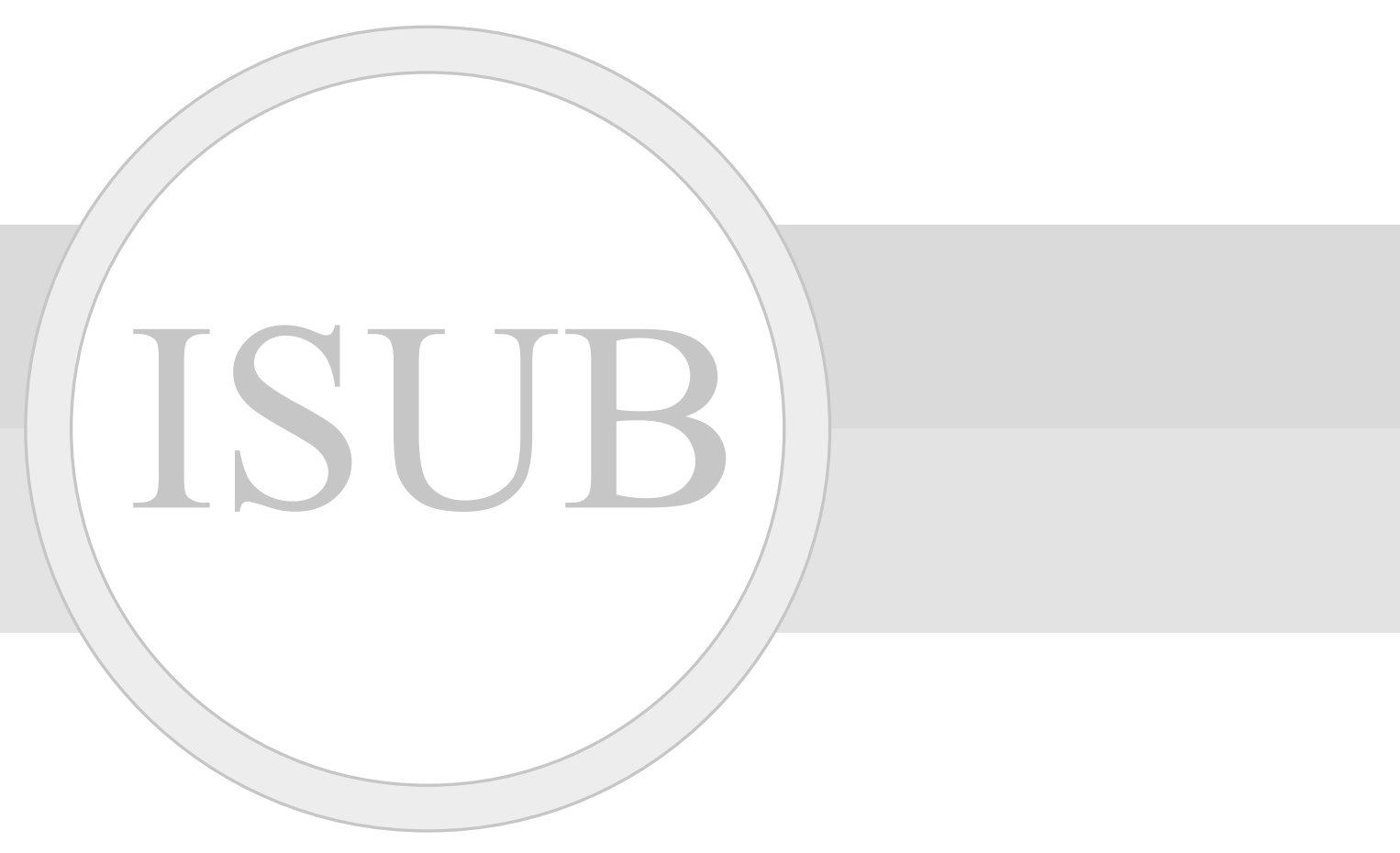

